\title{
Anti-progestins suppress the growth of established tumors induced by 7,12-dimethylbenz $(a)$ anthracene: Comparison between RU486 and a new 21-substituted-19-nor-progestin
}

\author{
RONALD D. WIEHLE ${ }^{1}$, KONSTANTIN CHRISTOV $^{2}$ and RAJENDRA MEHTA ${ }^{3}$ \\ ${ }^{1}$ Repros Therapeutics, Inc., 2408 Timberloch Place, B-7, The Woodlands, TX 77380; ${ }^{2}$ The University of Illinois at Chicago \\ College of Medicine, 840 South Wood Street; ${ }^{3}$ IIT Research Institute, 10 West 35th St., Chicago, IL 60616, USA
}

Received February 6, 2007; Accepted March 19, 2007

\begin{abstract}
In this report, we evaluate the effects of a 21substituted-19-nor-progestin, CDB-4124, on 7,12,-dimthylbenz( $a$ )anthracene (DMBA)-induced mammary carcinogenesis in rats in comparison with RU486. Sprague-Dawley female rats were treated with DMBA at 50 days of age in order to induce mammary tumors. When the tumors reached the size of $10-12 \mathrm{~mm}$, the animals were treated for 28 days with the vehicle, RU486, progesterone, CDB-4124 at various doses, or CDB-4124 plus progesterone. Anti-progestins resulted in the regression in the size of the existing tumors, and in the suppressed development of new tumors and tumor multiplicity. Progesterone treatment, however, increased the size and multiplicity. Progesterone rendered an increased number of growing tumors as compared to the regression in the antiprogesterone treatment groups. The combination of CDB4124 and high doses of progesterone opposed the efficacy of CDB-4124. The growth inhibitory effects of the anti-progestins were correlated with increased apoptosis and reduced cell proliferation. These results indicate that anti-progestins should be developed for the chemoprevention and treatment of hormone-responsive breast cancer.
\end{abstract}

\section{Introduction}

Approximately 200,000 American women were diagnosed with breast cancer in 2005 . Of those, almost $60 \%$ were free of metastatic disease at the time of their surgery although $30 \%$ of that same group will eventually have a recurrence. Women whose primary lesion contains estrogen (ER) and progesterone receptors $(\mathrm{PR})$ are primarily treated with hormone therapy using anti-ERs such as tamoxifen or aromatase

Correspondence to: Dr Ronald D. Wiehle, Repros Therapeutics Inc., 2408 Timberloch Place, B-7, The Woodlands, TX 77380, USA E-mail: rwiehle@reprosrx.com

Key words: anti-progestins, CDB-4124, RU486, carcinogenesis, apoptosis, proliferation, progesterone inhibitors. Nearly $70 \%$ of the ER- and PR-positive patients respond to tamoxifen. Although the presence of both the ER and PR status is crucial for a response and ER induces PR relatively little effort is diverted towards developing antiprogestins as possible modulators of breast cancer development and progression.

Unlike its role in the uterus as a differentiation agent that opposes the proliferative actions of ER, progesterone is mitogenic in the breast (1). The highest mitotic activity in breast tissue is found in the luteal phase (2,3). Clinically, women using medroxyprogesterone acetate as part of hormone replacement therapy (HRT) show a greater degree of terminal ductlobular unit proliferation (4). Perhaps the most provocative data of the last few years are those from the Women's Health Initiative (WHI). The initial reports showed a small but clearly higher risk of breast cancer in women taking an ER-progestinbased HRT for 5 years $(5,6)$. Recently, a follow-up study showed that women taking ER alone faced no such risk after 7 years (7). Although the patient populations were not strictly comparable (the 2002/3 reports were in post-menopausal women with a uterus whereas the 2006 report was conducted in women without a uterus), those data suggest that progesterone plays a role in the development of breast cancer. The enhanced risk of breast cancer in women on ER-progestin therapy over ER alone is consistent with increases in breast density (8), possibly due to increases in the size of lobules and terminal ducts.

Progestins have been shown to increase the incidence of spontaneous mammary tumors in dogs (9) and mice (10). In classical experimental tumor models, the development of 7,12,-dimthylbenz(a)anthracene (DMBA)-induced tumors was inhibited by ovariectomy and accellerated by progesterone $(11,12)$. When anti-progestins were used in this tumor model, the inhibition of mammary carcinogenesis was observed $(13,14)$. Moreover, tamoxifen and the anti-progestin, RU486, are potent suppressers of tumor growth when used together (14).

The 21-substituted 19-norprogestin (CDB-4124), was developed as an anti-progestin for several gynecological indications. Previous studies had shown that CDB-4124 lacks estrogenic, androgenic, anti-estrogenic, and anti-androgenic activities. Unlike RU486, CDB-4124 has only a weak antiglucocorticoid activity (15). In the present study, we 
Table I. Effect of treatments on tumor type and tumor number.

\begin{tabular}{|c|c|c|c|c|c|c|c|}
\hline Group & \multicolumn{2}{|c|}{ Treatment $^{\mathrm{a}}$} & $\begin{array}{l}\text { Incidence of } \\
\text { tumors }(\%)\end{array}$ & $\begin{array}{l}\text { ACA } \\
\text { per rat }\end{array}$ & $\begin{array}{l}\text { PCA } \\
\text { per rat }\end{array}$ & $\begin{array}{c}\mathrm{FA} / \mathrm{AF} \\
\text { no. }\end{array}$ & $\begin{array}{c}\mathrm{ACA}+\mathrm{PCA} \\
\text { per rat }\end{array}$ \\
\hline 1 & Control & Vehicle & $12 / 13(92)$ & 1.17 & 1 & 3 & 2.67 \\
\hline 2 & No DMBA control & Vehicle & $0 / 10(0)$ & 0 & 0 & 0 & 0 \\
\hline 3 & RU486 & $10 \mathrm{mg}^{\mathrm{b}}$ & $13 / 14(93)$ & 2.08 & 0.08 & 1 & 2.00 \\
\hline 4 & Progesterone $(\mathrm{P})$ & $10 \mathrm{mg}$ & $10 / 10(100)$ & 3.3 & 1.4 & 3 & 4.90 \\
\hline 5 & 4124 & $20 \mathrm{mg}$ & $13 / 13(100)$ & 1.31 & 0.08 & 3 & 1.38 \\
\hline 6 & & $10 \mathrm{mg}$ & $10 / 11(91)$ & 1.5 & 0.2 & 1 & 1.70 \\
\hline 7 & & $2 \mathrm{mg}$ & $11 / 12(92)$ & 1.45 & 0.09 & 2 & 1.55 \\
\hline 8 & & $1 \mathrm{mg}$ & $9 / 11(82)$ & 1.67 & 0.11 & 2 & 1.78 \\
\hline 9 & & $0.1 \mathrm{mg}$ & $12 / 12(100)$ & 1.17 & 0.83 & 3 & 2.25 \\
\hline 10 & $4124+P$ & $20+10 \mathrm{mg}$ & $8 / 10(80)$ & 1.89 & 0.11 & 1 & 2.00 \\
\hline 11 & & $10+10 \mathrm{mg}$ & $10 / 12(83)$ & 1.2 & 0 & 3 & 1.30 \\
\hline 12 & & $2+10 \mathrm{mg}$ & $10 / 11(91)$ & 2.8 & 0.6 & 1 & 3.50 \\
\hline 13 & & $1+10 \mathrm{mg}$ & $14 / 15(93)$ & 2.43 & 0.86 & 1 & 3.29 \\
\hline 14 & & $0.1+10 \mathrm{mg}$ & $11 / 11(100)$ & 2.55 & 1.09 & 0 & 3.73 \\
\hline
\end{tabular}

ACA, adenocarcinoma; PCA, papillary carcinoma; FA, fibroadenoma; AF, adenofibroma; DMBA, 7,12,-dimthylbenz $(a)$ anthracene. ${ }^{a}$ TX for 28 days after the appearance of the first tumor; ${ }^{\mathrm{b}} \mathrm{TX}$ at $10 \mathrm{mg} / \mathrm{kg}$ body weight.

determined the anti-progestational effects of CDB-4124 on chemically-induced mammary carcinogenesis in the rat.

\section{Materials and methods}

Materials. CDB-4124 (17 $\alpha$-acetoxy-21-methoxy-11ß[4N,N,dimethylaminophenyl]-19-norpregna-4,9-diene-3,20dione) was generously supplied by the NICHD though the assistance of Drs Richard Blye and HK Kim. DMBA, sesame oil, and RU486 were purchased from Sigma (St. Louis, MO, USA). Assays for serum progesterone, cortisol, and corticosterone were performed using a commercially-available ELISA kit from Diagnostic Systems Laboratory (Webster, TX, USA).

Animals, tumor induction and treatment. This study was approved by the Institutional Animal Care and Use Committee. Sprague-Dawley female rats were housed in individual cages with food and water available ad libitum. The animals were given $10 \mathrm{mg} / \mathrm{kg}$ body weight of DMBA at 50 days of age. One group of 14 rats (Group 2) received sesame oil at 50 days of age instead of DMBA to serve as the no-DMBA control. The animals were weighed and palpated weekly along the milk line for any sign of lesions or swellings. Tumor nodules were noted and measured weekly in two dimensions with calipers. When tumors grew to a size of 10$12 \mathrm{~mm}$, the individual animal was randomized into one of 14 groups (Table I). The rats were treated for 28 days with antiprogestins, progesterone or the vehicle. The groups were divided as follows: Group 1, daily subcutaneous (s.c.) injections of the vehicle (10\% ethanol in sesame oil); Group 2, daily injections of the vehicle on a schedule decided beforehand in order to simulate the initiation of treatment over a three-month time period; Groups 3 and 4, daily s.c. injections of RU486 or micronized progesterone in the vehicle at $10 \mathrm{mg} /$ $\mathrm{kg}$ body weight, respectively, Groups 5 through 9, $20 \mathrm{mg} / \mathrm{kg}$, $10 \mathrm{mg} / \mathrm{kg}, 2 \mathrm{mg} / \mathrm{kg}, 1 \mathrm{mg} / \mathrm{kg}, 0.1 \mathrm{mg} / \mathrm{kg}$, respectively, Groups 10 through 14 , similar treatment as groups 5 through 9 except that CDB-4124 at various dosages was combined with $10 \mathrm{mg}$ / $\mathrm{kg}$ progesterone.

Examination of tumors and sera. Animals were sacrificed 3-5 days after the end of the 28-day treatment period, blood was drawn, and tumors were removed, weighed, measured, inspected, and the portions were frozen and/or placed in $10 \%$ phosphate buffered formalin for histopathology. The tissue samples were cut and stained with H\&E and were evaluated for histopathological classification. The animals were assessed three times for their levels of progesterone: Initially, when they were about to go on treatment, a second time after 21 days of treatment and finally after treatment at sacrifice which was 2-4 days after the last s.c. injection. All blood samples were taken by heart puncture; serum was prepared and held frozen at $-40^{\circ} \mathrm{C}$. The levels of the steroid hormones progesterone, cortisol, and corticosterone were determined by ELISA.

Proliferation and apoptosis markers. In order to assess the effects of progestins and anti-progestins on cell proliferation, tissue sections derived from the tumors were examined by the Ki-67 antibody and immunohistochemistry. The Ki-67 antibody was purchased from Neomarkers (Fremont, CA, USA). Apoptosis was evaluated by an apoptosis hybridization kit obtained from Oncor, Gaithersburg, MD, USA. The cells in apoptosis were evaluated in the peripheral areas of the tumors and far from necrosis. At least 1,000 cells per tumor section were evaluated (16). 


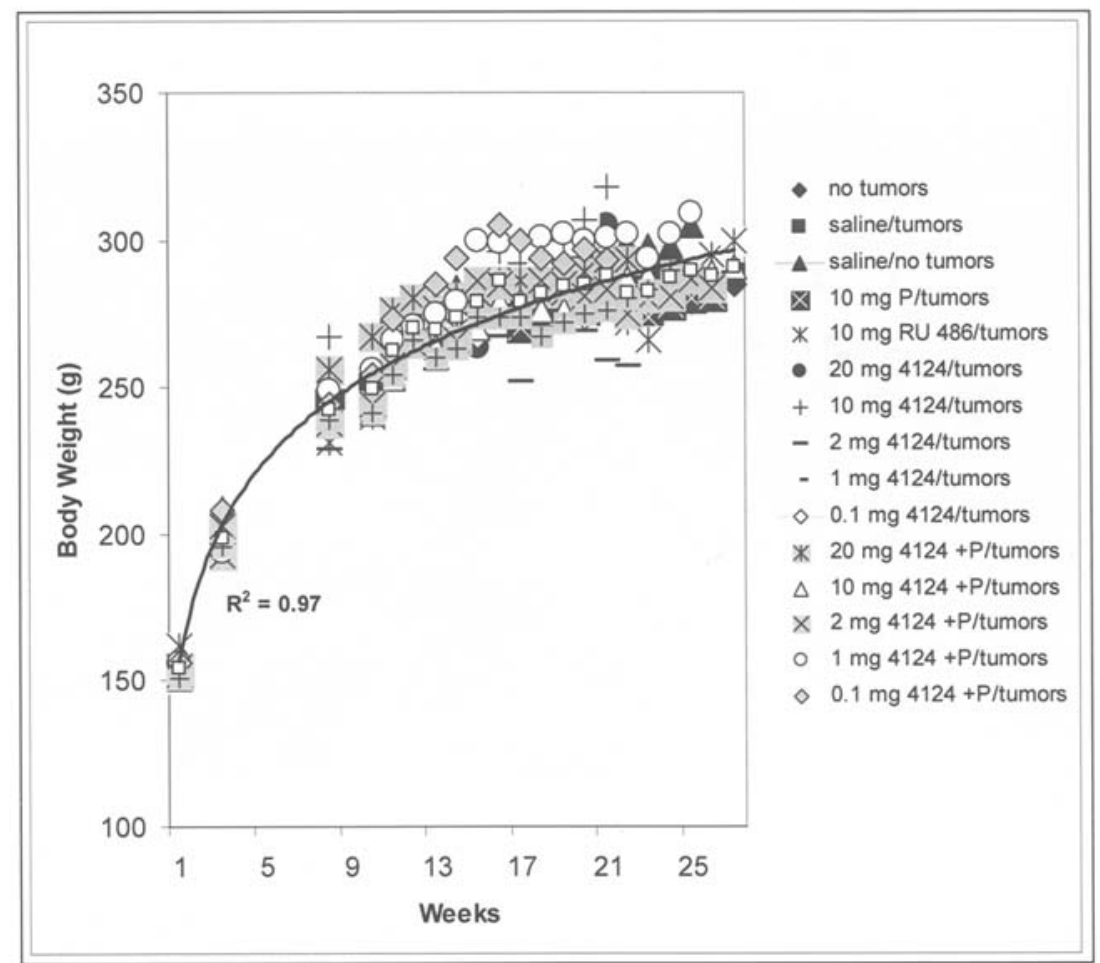

Figure 1. Body weights of the rats treated during the study. The animals were weighed weekly during the 27 -week study period. The effects of no treatment and the various treatments on body weight are given.

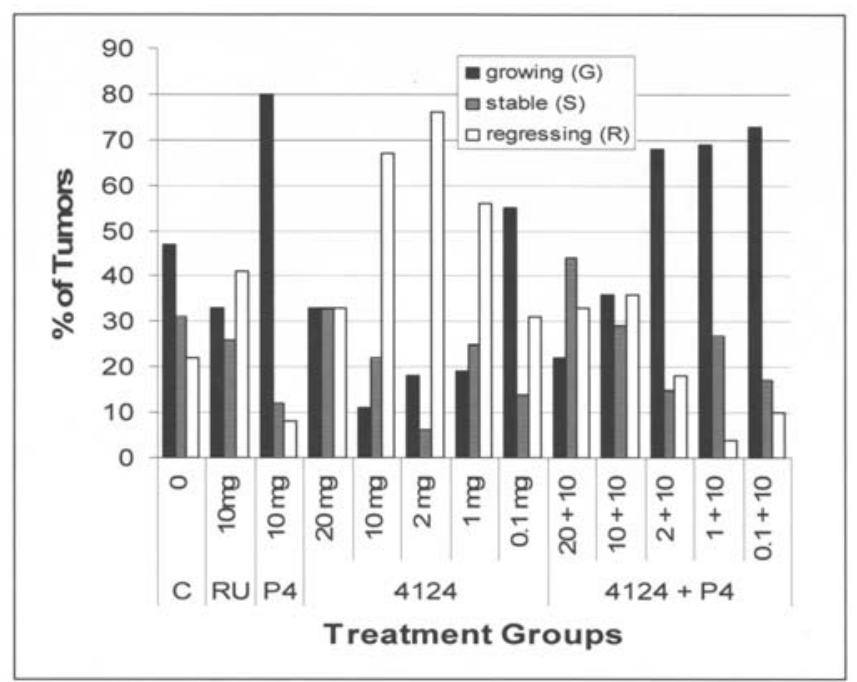

Figure 2. Rat tumor growth pattern under treatments. Individual tumors from animals with tumors in the study were assessed for tumor growth based on weekly measurements with calipers. Tumors that increased in cross-sectional area by at least $33 \%$ over the 28 -day inspection period were considered to be growing (black boses). Those that decreased by $33 \%$ over the same period were considered to be regresseing (white boxes). Others were considered to be static (lined boxes). Shown are the percentages of each type of growth pattern for each treatment group that demonstrated tumors.

Statistical analysis. Analysis was performed using Statgraphics Plus. Differences among the groups were determined by ANOVA if the group means were well-distributed. Otherwise the Kruskal-Wallis test was used. Differences in the means were evaluated using the Student's t-test if the groups met the criterion of being neither kurtotic nor skewed. Otherwise, the non-parametric Mann-Whitney-Wilcoxin test was used. If the same rats were being assessed sequentially, a paired t-test was used. If the data could be placed into the groups for comparison, Fisher's exact test was employed.

\section{Results}

Effects of anti-progestins on body growth. We compared the weights of the control animals with those receiving hormonal treatment to better assess toxicity, especially that due to CDB-4124 (Fig. 1). The animals were weighed weekly during the 27 -week study period. We did not find any significant differences in the animals' weights in the treated vs the control animals at the end of the experiments indicating that this novel anti-progestin is not toxic, even at a high dose level. Tumors appeared as early as 39 days after oral gavage and as late as 194 days. The mean latency period for tumor appearance was $106 \pm 30$ days. There were no differences between the groups receiving DMBA in terms of latency $(\mathrm{p}=0.54$, Kruskal-Wallis test).

Effects of anti-progestins on tumor progession. In order to evaluate the effects of CDB-4124, RU486 and progesterone on tumor development and progression, growth kinetics and tumor size were monitored during the treatment period. Tumors that increased in cross-sectional area by at least $33 \%$ over the 28-day inspection period were considered to be growing. Those that decreased by $33 \%$ were considered to be regressing. Others were considered to be static. As shown in Fig. 2, progesterone treatment resulted in an increased number of growing tumors. Although the proportion of tumors 
Table II. Effects of treatments on tumor number, size, and tumor burden.

\begin{tabular}{|c|c|c|c|c|c|c|c|}
\hline \multirow{2}{*}{$\begin{array}{l}\text { Group } \\
1\end{array}$} & \multicolumn{2}{|c|}{ Treatment $^{\mathrm{a}}$} & $\begin{array}{l}\text { Number } \\
\text { of tumors }\end{array}$ & $\begin{array}{c}\mathrm{TB} \\
\mathrm{g} / \mathrm{rat}\end{array}$ & $\begin{array}{c}\text { Tumor } \\
\text { mean }(\mathrm{g})\end{array}$ & $\begin{array}{c}\text { Weight } \\
\text { median }(\mathrm{g})\end{array}$ & MWW test ${ }^{b}$ \\
\hline & Control & Vehicle & 32 & 4.7 & 1.91 & 0.8 & \\
\hline 2 & No DMBA control & Vehicle & 0 & 0 & 0 & 0 & \\
\hline 3 & RU486 & $10 \mathrm{mg}^{\mathrm{c}}$ & 27 & 2.47 & 1.19 & 0.16 & $\mathrm{p}=0.012$ \\
\hline 4 & Progesterone $(\mathrm{P})$ & $10 \mathrm{mg}$ & 49 & 7.34 & 1.5 & 0.5 & $\mathrm{p}=0.42$ \\
\hline 5 & 4124 & $20 \mathrm{mg}$ & 20 & 4.71 & 3.4 & 0.125 & $\mathrm{p}=0.066$ \\
\hline 6 & & $10 \mathrm{mg}$ & 18 & 0.48 & 0.26 & 0.075 & $\mathrm{p}=0.0003$ \\
\hline 7 & & $2 \mathrm{mg}$ & 17 & 4.61 & 2.98 & 0.09 & $\mathrm{p}=0.012$ \\
\hline 8 & & $1 \mathrm{mg}$ & 16 & 0.94 & 0.53 & 0.17 & $\mathrm{p}=0.0009$ \\
\hline 9 & & $0.1 \mathrm{mg}$ & 29 & 5.1 & 2.26 & 0.77 & $\mathrm{p}=0.99$ \\
\hline 10 & $4124+\mathrm{P}$ & $20+10 \mathrm{mg}$ & 18 & 0.92 & 0.46 & 0.18 & $\mathrm{p}=0.005$ \\
\hline 11 & & $10+10 \mathrm{mg}$ & 14 & 3.82 & 2.73 & 0.185 & $\mathrm{p}=0.013$ \\
\hline 12 & & $2+10 \mathrm{mg}$ & 34 & 5.8 & 1.96 & 0.45 & $\mathrm{p}=0.19$ \\
\hline 13 & & $1+10 \mathrm{mg}$ & 45 & 4.28 & 1.19 & 0.49 & $\mathrm{p}=0.27$ \\
\hline 14 & & $0.1+10 \mathrm{mg}$ & 41 & 6.16 & 1.65 & 0.49 & $\mathrm{p}=0.66$ \\
\hline
\end{tabular}

DMBA, 7,12,-dimthylbenz $(a)$ anthracene. ${ }^{\text {aTX for }} 28$ days after the appearance of the first tumor; ${ }^{\mathrm{b}}$ compared to the control median tumor weight; ${ }^{\mathrm{T} X}$ at $10 \mathrm{mg} / \mathrm{kg}$ body weight.

regressing in the group given progesterone $(8 \%)$ was statistically the same as the controls, the proportion of the growing tumors was significantly higher $(\mathrm{p}<0.004$, Fisher's exact test), $80 \%$. Treatment with RU486 led to an apparent increase in the proportion of regressing tumors as compared to the controls, although this was not statistically significant. Unlike progesterone, the anti-progestin, CDB-4124, at $10 \mathrm{mg} / \mathrm{kg}$ body weight decreased the proportion of growing tumors $(\mathrm{p}<0.013)$ and increased the proportion of tumors that regressed $(p<0.003)$. Results showed that $70 \%$ of the tumors were regressing after the treatment with CDB-4124. There was an apparent dose-dependency and only the lowest dose of CDB4124 was ineffectual. The effects of CBD-4124 were abolished when the animals were treated with additional progesterone at a ratio that was 5-fold or higher. Progesterone, given at lower ratios was unable to override the effects of CDB-4124. In terms of growth rate, a dose of $10 \mathrm{mg} / \mathrm{kg}$ CDB-4124 was more efficacious as compared to $20 \mathrm{mg} / \mathrm{kg}$, suggesting that at high doses, CDB-4124 could have some progesterone agonist activity, although the effects of $20 \mathrm{mg} / \mathrm{kg}$ CDB-4124 on tumor growth did not approach those of progesterone $(\mathrm{p}=0.0008$, Fisher's exact test, two-tailed). However, the $20 \mathrm{mg} / \mathrm{kg}$ dose also significantly increased circulating progesterone levels and the effects were dose-dependent (see below).

Tumor number at necropsy, pathological type and size. Histologically four types of tumors were identified (Table I): Adenocarcinomas (ACAs), papillary carcinomas (PCAs), a fibrosarcoma, and fibroadenomas or adenofibromas (FA or $\mathrm{AF}$ ), the latter two tumor types were not considered to represent frank malignancies. The minimum number of tumors for the initiation of treatment was $\geq 1$ given that the largest ('lead') tumor could be accompanied one or more smaller tumors that did not reach the minimum size. The multiplicity of ACA plus PCA in rats treated with the vehicle alone was 2.7 tumors per rat at the time of sacrifice. (The $\mathrm{ACA}+\mathrm{PCA}$ column is not always the addition of the ACA and PCA per rat columns as the tumors could be mixed types.) Group 2 (rats not given carcinogen) had no tumors. The addition of progesterone increased the average number of tumors per rat to 4.9. Treatment with CDB-4124 had major effects on reducing the number of tumors. The average multiplicity across the highest 4 treatment groups that was most effective (i.e. $20,10,2,1 \mathrm{mg} / \mathrm{kg} /$ day) was 1.58 tumors/ rat. This reduction in tumor number not only reduced the growth of existing tumors but also prevented the occurrence of new tumors in these animals. Table II shows the effects of progesterone, RU486, and CDB-4124 on median tumor size and mean total tumor weight per animal (tumor burden). Results in Table II are those for ACA, PCA, and mixed ACA/ PCA, but the FA or AF tumors are excluded. Progesterone clearly increased the tumor burden and median size of the tumors. However, the values were not statistically significant compared to those of the control ( $p>0.4$, Mann-WhitneyWilcoxin test). The progesterone data are in sharp contrast to those of the anti-progestins. RU486 and CDB-4124 lowered tumor burden and the median tumor sizes, 5-fold in the case of RU486 ( $<<0.01)$ and 10-fold for CDB-4124 ( $<<0.001)$. Reductions in tumor burden and tumor size in the other groups were consistent with CDB-4124 affecting tumor size at 2 and $1 \mathrm{mg} / \mathrm{kg}$. CDB-4124 was ineffective at the lowest treatment level and the highest dose of CDB-4124 (20 mg/kg) was not as effective as the $10 \mathrm{mg} / \mathrm{kg}$ dose. It should be noted that some tumors regressed completely and were no longer palpable. Among 11 tumors of this type that were followed-up during treatment, we found structures at necropsy that were 
Table III. Proliferating tumor cells by Ki-67.

\begin{tabular}{clccc}
\hline Group & \multicolumn{1}{c}{ Treatment } & \% Cells positive & $\begin{array}{c}\text { Compared to } \\
\text { controls (t-test) }\end{array}$ & $\mathrm{n}$ \\
\hline 1 & Control tumors & $13.5 \pm 7.8$ & - & 12 \\
3 & RU486 $(10 \mathrm{mg} / \mathrm{kg})$ & $12.9 \pm 7.0$ & $\mathrm{p}=0.85$ & 10 \\
4 & Progesterone $(\mathrm{P} 4)(10 \mathrm{mg} / \mathrm{kg})$ & $25.7 \pm 5.8$ & $\mathrm{p}=0.0007$ & 9 \\
6 & $4124(10 \mathrm{mg} / \mathrm{kg})$ & $5.1 \pm 4.2$ & $\mathrm{p}=0.00$ & 7 \\
11 & $4124+\mathrm{P} 4(10+10)$ & $15.5 \pm 12.2$ & $\mathrm{p}=0.66$ & 8 \\
& ANOVA & $\mathrm{p}=0.0001$ & & \\
\hline
\end{tabular}

Table IV. Apoptosis (\% of cells in tumors in programmed cell death).

\begin{tabular}{llcc}
\hline Group & \multicolumn{1}{c}{ Treatment } & $\begin{array}{c}\text { \% Cells } \\
\text { positive }\end{array}$ & $\begin{array}{c}\text { Compared to } \\
\text { controls (t-test) }\end{array}$ \\
\hline 1 & Control tumors & $0.81 \pm 0.31$ & - \\
3 & RU486 $(10 \mathrm{mg} / \mathrm{kg})$ & $3.34 \pm 2.57$ & $\mathrm{p}=0.003$ \\
4 & Progesterone $(\mathrm{P} 4)(10 \mathrm{mg} / \mathrm{kg})$ & $1.28 \pm 0.51$ & $\mathrm{p}=0.015$ \\
6 & $4124(10 \mathrm{mg} / \mathrm{kg})$ & $3.84 \pm 3.10$ & $\mathrm{p}=0.003$ \\
11 & $4124+\mathrm{P} 4(10+10)$ & $3.78 \pm 4.93$ & $\mathrm{p}=0.0496$ \\
\hline
\end{tabular}

cystic filled with hemorrhagic substance, suggesting regression. These structures were found only in the groups treated with RU486 ( $n=2)$, in those treated with CDB-4124 at 20, 10, 2, or $1 \mathrm{mg} / \mathrm{kg}(\mathrm{n}=7)$, or in those treated with $20 \mathrm{mg} / \mathrm{kg}$ CDB4124 plus $10 \mathrm{mg} / \mathrm{kg}$ progesterone $(\mathrm{n}=2)$. Since they could not be evaluated histologically, we cannot confirm their identity. Nonetheless, these results suggest that anti-progestins can completely regress tumors.

Tumor proliferation and apoptosis. In order to determine the potential mechanism of tumor growth inhibition by the antiprogestins, we assessed cell proliferation and apoptosis in the treated and the control animals. We evaluated 46 individual rat tumors for cell proliferation by, the Ki-67 antibody and the ABC kit, and for apoptosis by the TUNEL assay. Although many tumors in Groups 3 and 6 were reduced in size following treatment and the blocks were too small to be re-cut, we were able to re-cut 7-12 ACAs from Groups 1,3, 4, 6, and 11. The results for the values of KI-67 and apoptotic cells are given in Table III. We found that progesterone increased the percentage of proliferating cells compared to controls and CDB-4124-treated animals. Progesterone led to the highest proportion of cells proliferating and that growth was beyond the one seen in the control, RU486, or CDB-4124 plus progesterone groups. Treatment with CDB-4124 alone led to a lower proportion of Ki-67-positive cells than any other treatment and the proportion was less than the one seen in the controls. The effects of CDB-4124 were statistically different than RU486 ( $\mathrm{p}=0.021$, two-tailed t-test). The effects of CDB-4124 were also different than CDB-4124 + P4 ( $p=0.048$, t-test). Moreover, treatment with CDB-4124 plus P4 led to less proliferating cells than $\mathrm{P} 4$ alone $(\mathrm{p}=0.030$, $\mathrm{t}$-test $)$. Proliferation declined in the groups in the following order: progesterone (most proliferation) $>$ control $=$ RU486 $=$ CDB4124 + progesterone $>$ CDB-4124 alone. Thus, our data indicate that CDB-4124 decreased proliferating cells even in the presence of an equal amount of added progesterone.

Analyses of apoptosis indicated a clear difference among the treatment groups with those of the control untreated animals (Table IV). A post-analysis by the Multiple Range Test indicated that CDB-4124 plus progesterone induced higher apoptosis than the control or progesterone-treated animals. Moreover, RU486, CDB-4124, and CDB-4124 plus progesterone induced higher apoptotic cell death than observed in the control tumors. The effects of treatment with CDB4124 were not different than RU486 ( $\mathrm{p}=0.73$, t-test). Similarly, the effects of CDB-4124 were the same as CDB-4124+ P4 $(\mathrm{p}=0.98$, $\mathrm{t}$-test $)$. These results suggest that, in the presence of approximately equal amounts of progesterone, tumors respond to the anti-progestin, CDB-4124, with apoptosis. On the contrary, CDB-4124 leads to increased apoptosis compared to $\mathrm{P} 4$ ( $\mathrm{p}=0.020$, t-test). There is no apparent synergism between CDB-4124 and progesterone.

Serum hormone levels. The concentrations of steroid hormones were determined three times during the study including on day 0 and day 21 as well as at the time of sacrifice (3-5 days after the last dose). There was no difference in the serum progesterone levels amongst the fourteen groups before treatment ( $\mathrm{p}=0.49$, ANOVA) or after treatment $(\mathrm{p}=0.35$, ANOVA), 
Table V. Effect of treatment on serum progesterone.

Serum progesterone in $\mathrm{ng} / \mathrm{ml}$

\begin{tabular}{|c|c|c|c|c|c|}
\hline Group & Treatr & & Before TxT & During TxT & After TxT \\
\hline 1 & Control & Vehicle & $53 \pm 37$ & $42 \pm 15$ & $46 \pm 27$ \\
\hline 2 & No DMBA control & Vehicle & $47 \pm 18$ & $50 \pm 25$ & $45 \pm 18$ \\
\hline 3 & RU486 & $10 \mathrm{mg}$ & $58 \pm 19$ & $72 \pm 30^{\mathrm{a}}$ & $52 \pm 20$ \\
\hline 4 & Progesterone (P4) & $10 \mathrm{mg}$ & $51 \pm 18$ & $55 \pm 21$ & $54 \pm 11$ \\
\hline 5 & 4124 & $20 \mathrm{mg}$ & $61 \pm 24$ & $96 \pm 27^{a}$ & $58 \pm 11$ \\
\hline 6 & & $10 \mathrm{mg}$ & $52 \pm 28$ & $77 \pm 21^{\mathrm{a}}$ & $43 \pm 33$ \\
\hline 7 & & $2 \mathrm{mg}$ & $59 \pm 22$ & $74 \pm 16^{a}$ & $56 \pm 19$ \\
\hline 8 & & $1 \mathrm{mg}$ & $64 \pm 24$ & $47 \pm 21$ & $42 \pm 30$ \\
\hline 9 & & $0.1 \mathrm{mg}$ & $54 \pm 20$ & $53 \pm 25$ & $53 \pm 28$ \\
\hline 10 & $4124+\mathrm{P} 4$ & $20+10 \mathrm{mg}$ & $43 \pm 16$ & $80 \pm 21^{\mathrm{a}, \mathrm{b}}$ & $66 \pm 32$ \\
\hline 11 & & $10+10 \mathrm{mg}$ & $52 \pm 18$ & $74 \pm 12^{\mathrm{a}, \mathrm{b}}$ & $55 \pm 14$ \\
\hline 12 & & $2+10 \mathrm{mg}$ & $46 \pm 24$ & $64 \pm 15^{a}$ & $55 \pm 14$ \\
\hline 13 & & $1+10 \mathrm{mg}$ & $58 \pm 20$ & $70 \pm 19^{a}$ & $40 \pm 18$ \\
\hline 14 & & $0.1+10 \mathrm{mg}$ & $55 \pm 17$ & $57 \pm 16$ & $41 \pm 18$ \\
\hline
\end{tabular}

DMBA, 7,12,-dimthylbenz ( $a$ anthracene. ${ }^{a}$ Different from the control; bdifferent from P4.

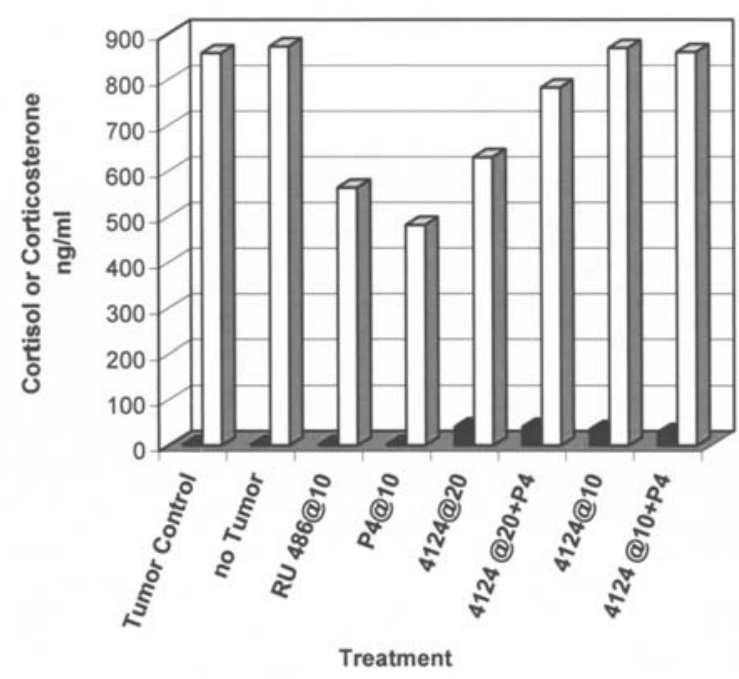

Figure 3. Effect of 4124 on serum glucocorticoids. We assessed the levels of corticosterone at sacrifice in the groups that showed the strongest effects on tumor growth: 4124 at 120 and $10 \mathrm{mg} / \mathrm{kg}$. For comparison, we also demonstrate the groups that received $20 \mathrm{mg} / \mathrm{kg} 4124 \mathrm{plus} 10 \mathrm{mg} / \mathrm{kg}$ progesterone, $10 \mathrm{mg} / \mathrm{kg} 4124 \mathrm{plus} 10 \mathrm{mg} / \mathrm{kg}$ progesterone, $10 \mathrm{mg} / \mathrm{kg} \mathrm{RU} 486,10 \mathrm{mg} / \mathrm{kg}$ progesterone alone, the control group, and the group that did not receive 7,12 ,-dimthylbenz(a)anthracene (no tumors). The levels of corticosterone observed were 10-40 times higher than those of cortisol. The grey boxes represent the serum cortisol levels; the white boxes represent the serum corticosterone levels.

but significant changes were found with treatment $(\mathrm{p}=0.000$, ANOVA). Many regimens raised progesterone compared to the controls, especially in those groups receiving the highest amounts of RU486 and CDB-4124 (Table V). The CDB-4124 $20 \mathrm{mg} / \mathrm{kg}$ group was clearly the most effective amongst the groups by the Multiple Range Test. Changes in serum progesterone with RU486 were in the direction of increases but failed to reach statistical significance ( $\mathrm{p}=0.098$, paired ttest). For those groups receiving both CDB-4124 and exogenous progesterone, the four highest CDB-4124 dose groups also led to increased serum progesterone compared to the controls and, the top two, to the progesterone alone group. Treatment with CDB-4124 raised serum progesterone over levels found before treatment for the $20 \mathrm{mg} / \mathrm{kg}$ ( $\mathrm{p}=0.007$, paired t-test) and $10 \mathrm{mg} / \mathrm{kg}(\mathrm{p}=0.013)$ dose levels. This was also true for the top three groups receiving both CDB-4124 and progesterone. Serum progesterone returned to day 0 levels for all the groups except the group receiving CDB-4124 at $20 \mathrm{mg} / \mathrm{kg}$ plus progesterone which failed to demonstrate a drop in serum progesterone when treatment was withdrawn ( $p=0.004$, paired t-test, one-tailed). There was no increase in the concentration of progesterone associated with the progesterone-only treatment. The failure of progesterone alone to significantly raise its own serum concentration was perplexing but could have been due to the fact that high exogenous progesterone suppressed endogenous production. Exogenous progesterone could also have been metabolized between the s.c. injection and the blood draw which was performed 20-24 h later.

There were no differences among the groups receiving CDB-4124 with or without additional progesterone in terms of corticosterone levels during treatment, although exogenous progesterone suppressed the level of corticosterone $(\mathrm{p}=0.042$, t-test). The levels of cortisol were much lower than those of corticosterone (Fig. 3). There was a strong positive correlation between the cortisol and corticosterone levels only for the RU486 $\left(\mathrm{R}^{2}=0.845\right)$, CDB-4124 at $20 \mathrm{mg} / \mathrm{kg}\left(\mathrm{R}^{2}=0.783\right)$ and the $\mathrm{CDB}-4124$ at $10 \mathrm{mg} / \mathrm{kg}\left(\mathrm{R}^{2}=0.818\right)$ groups. 


\section{Discussion}

In the present study, we showed that CDB-4124 is able to suppress the growth of DMBA-induced tumors of the rat mammary gland. The suppression included a reduction in the size and number of mammary tumors. Our finding that progesterone can enhance the development of DMBAinduced mammary tumors is in agreement with the classical studies of Huggins et al (12). The finding that progesterone itself was proliferative and tumor-enhancing, illustrates the importance of suppressing progesterone in animals with established or nascent tumors of the mammary gland.

Our results are most compatible, with and support the effects seen with known anti-progestins in rats with DBMAinduced tumors of the mammary gland. When the antiprogestin-antiglucocorticoid, RU486, was used daily for 3 weeks after the initiation of carcinogenesis, a delay in tumor appearance was seen. Also, when RU486 was used to treat animals with established tumors, a decrease was seen in tumor size compared to the controls (13). In that last study, there was an elevation of serum ER and progesterone. The elevation in progesterone that we observed in this study occurred only at the highest dose of CDB-4124. The anti-progestins, Org 31710, Org 33628 (14,17), ZK112.993 (18) and ZK 299, (19) are all more potent than RU486 in rodent models of breast cancer. In the case of ZK 299, its full antagonism can contribute to its potency. Progesterone-induced growth in tamoxifen-suppressed DMBA tumors can also be blocked by RU486 (20). Indeed, the combination of tamoxifen and RU486 is a potent suppresser of tumor growth analogous to chemical castration (21). The anti-ER, ICI 164384, enhances the ability of ZK 299 to reduce tumors in the MXT mouse mammary tumor model (22). Studies in progesterone receptor knockout mice have shown that chemical carcinogens that specifically target the mammary gland depend upon the progesterone receptor $(23,24)$. RU486 and CDB-4124 raised serum progesterone only at higher doses, reminiscent of the results observed by Bakker et al (13), a finding that could reflect the limits of their doses.

Two small clinical trials in women with metastatic breast cancer have shown that RU486 has some efficacy against the disease $(25,26)$ although a larger Phase II trial failed to do so (27). In the latter study, symptoms of adrenal insufficiency were observed.

The above is not unexpected given that a rise in serum cortisol was seen when RU486 was used to treat patients with endometriosis (28). Anti-glucocorticoid activity would be likely to lead to higher ACTH and increased cortisol in humans and corticosterone in rodents. In fact, in a study sited above, patients were anovulatory as expected (29) but serum ER levels remained consistent with mid-follicular phase although there was evidence for hypercortisolemia and ACTH excess. When compared side-by-side, CDB-4124 and its major metabolite have much less anti-glucocorticoid activity (15). In the present study, neither RU486 nor CDB-4124 raised corticosterone, the primary glucocorticoid of the rat. The levels of cortisol itself were many times lower than those of corticosterone in all the groups tested. Other differences between the two compounds in the uterus are currently under study. Potential anti-glucocorticoid effects mitigate against the long-term use of RU486. Thus, although RU486 can serve as the paradigm for this class of anti-progestin-type drugs, the dose and outcomes must be measured against possible anti-glucocorticoid effects. A critical question is whether an anti-progestin lacking strong anti-glucocorticoid activity would be as effective. Clearly, lower anti-glucocorticoid activity can enhance drug utility by allowing higher dosage.

In the present study, there is a distinction between the new anti-progestin and RU486, an anti-progestin found to be effective against DMBA-induced breast cancer in rats. CDB-4124, at the same dose, is more efficacious than RU486. This difference could be due to the fact that whereas both compounds are potent anti-progestins, RU486 has also been shown to bind to the glucocorticoid receptor and to act as an anti-glucocorticoid.

The current study indicates that CDB-4124 decreased the proliferation of mammary tumor cells. Both RU486 and CDB-4124 were effective in this model with CDB-4124 being more effective. When progesterone antagonists block proliferation in vitro, this activity relates to arresting cells in G0/G1 and enhancing terminal differentiation (30) or apoptosis (31). It has long been known that RU486 leads to cell shrinkage, chromatin condensation, and pyknosis (32), typical of apoptosis. Although RU486 and CDB-4124 were both strong inducers of apoptosis, the major difference between them is that CDB-4124 was better able to reduce proliferation than RU486.

Treatment with either RU486 or CDB-4124 reduced the tumor multiplicity in the period following the identification of the initial tumor. This indicated that the anti-progestins could also have a chemopreventive effect on the development of new tumors. A recent report has indicated that mammary carcinogenesis in mice carrying mutations in the susceptibility gene, BRCA1, is preventable with treatment with RU486 (33). However, the goal of chemoprevention with compounds such as CDB-4124 may have to be approached cautiously given the substantial costs and efforts involved. The current study provides supportive results for developing CDB-4124 for possible adjuvant therapy for breast cancer patients.

\section{Acknowledgements}

This study was supported by an SBIR grant R43-CA/HD91483-01A1 (NCI). The authors would like to thank Deborah Britnell for her excellent technical work and Dr Mitzi Martinez for her veterinary skills, assistance with necropsies, and scientific advice.

\section{References}

1. Clarke CL and Sutherland RL: Progestin regulation of cellular proliferation. Endocrine Rev 11: 266-301, 1990.

2. Longacre TC and Barto SA: A correlative morphologic study of human breast and endometrium in the menstrual cycle. Am J Surg Pathol 10: 382-393, 1986.

3. Going JJ, Anderson TJ, Battersby S and Macintyre CCA: Proliferative and secretory activity in human breast during natural and artificial menstrual cycles. Am J Pathol 130: 193-204, 1988.

4. Hofseth LJ, Raafat AM, Osuch JR, Pathak DR, Slomski CA and Haslam SZ: Hormone replacement therapy with estrogen or estrogen plus medroxyprogesterone acetate is associated with increased epithelial proliferation in the normal postmenopausal breast. J Clin Endocrinol Metab 84: 4559-4565, 1999. 
5. Rossouw JE, Anderson GL, Prentice RL, et al: Risks and benefits of estrogen plus progestin in healthy postmenopausal women: principal results from the Women's Health Initiative randomized controlled trial. JAMA 288: 321-333, 2002.

6. Chlebowski RT, Hendrix SL, Langer RD, et al: Influence of estrogen plus progestin on breast cancer and mammography in healthy postmenopausal women: the Women's Health Initiative Randomized Trial. JAMA 289: 3243-3253, 2003.

7. Stefanick ML, Anderson GL, Margolis KL, et al: Effects of conjugated equine estrogens on breast cancer and mammography screening in postmenopausal women with hysterectomy. JAMA 295: 1647-1657, 2006.

8. Pike MC: The role of mammographic density in evaluating changes in breast cancer risk. Gynecol Endocrinol 21 (Suppl 1): $1-5,2005$.

9. Frank DW, Kitron KT, Murchism TE, et al: Mammary tumors and serum hormones in the bitch treated with medroxy-progesterone acetate or progesterone for four years. Fertil Steril 31: 340-346, 1979.

10. Nagasawa H, Aoki M, Sakagami N and Ishida M: Medroxyprogesterone acetate enhances spontaneous mammary tumorigenesis and uterine adenomyosis in mice. Breast Cancer Res Treat 12: 59-66, 1988.

11. Huggins $C$ and Yang NC: Induction and extinction of mammary cancer. A striking effect of hydrocarbons permits analysis of mechanisms of causes and cure of breast cancer. Science 137: 257-261, 1962 .

12. Huggins C, Moon RC and Morii S: Extinction of experimental mammary cancer. I. Estradiol-17beta and progesterone. Proc Natl Acad Sci USA 48: 379-385, 1962.

13. Bakker GH, Setyono-Han B, Henkelman MS, et al: Comparison of the actions of the anti-progestin mifepristone (RU486), the progestin megestrol acetate, the LHRH analog buserelin, and ovariectomy in treatment of rat mammary tumors. Cancer Treat Rep 71: 1021-1027, 1987.

14. Bakker GH, Setyono-Han B, Portengen H, De Jong FH, Foekens JA and Klijn JGM: Treatment of breast cancer with different anti-progestins: preclinical and clinical studies. J Steroid Biochem Mol Biol 37: 789-794, 1990.

15. Attardi B, Burgenson J, Hild S, Reel JR and Blye RP: CDB4124 and its putative monodemethylated metabolite, CDB4453 , are potent anti-progestins with reduced antiglucocorticoid activity: in vitro comparison to mifepristone and CDB-2914. Mol Cell Endocrinol 188: 111-123, 2002.

16. Christov, K., Ikui A, Shilkaitis, A, et al: Cell proliferation, apoptosis, and expression of cyclin D1 and cyclin E as potential biomarkers in tamoxifen-treated mammary tumors. Breast Cancer Res Treat 77: 253-264, 2003.

17. Kloosterboer HJ, Deckers GH, Schoonen WGEJ, et al: Preclinical experience with two selective progesterone receptor modulators on breast and endometrium. Steroids 65: 733-740, 2000.

18. Schneider MR, Michna H, Nishino Y, Neef G and el Etreby MF: Tumor-inhibiting potential of ZK 112.993, a new progesterone antagonist, in hormone-sensitive, experimental rodent and human mammary tumors. Anticancer Res 10: 683-687, 1990.

19. Michna H, Schneider MR, Nishino Y and Etreby MF: Antitumor activity of the anti-progestins ZK 98.299 and RU 38.486 in hormone dependent rat and mouse mammary tumors: mechanistic studies. Breast Cancer Res Treat 14: 275-288, 1989.
20. Robinson SP and Jordan VC: Reversal of the antitumor effects of tamoxifen by progesterone in the 7,12-dimethylbenzanthracene-induced rat mammary carcinoma model. Cancer Res 47: 5386-5390, 1987

21. Bakker GH, Setyono-Han B, Portengen H, De Jong FH, Foekens JA and Klijn JGM: Endocrine and antitumor effects of combined treatment with an anti-progestin and antiestrogen or luteinizing hormone-releasing hormone agonist in female rats bearing mammary tumors. Endocrinology 125: 1593-1598, 1989.

22. Nichino Y, Schneider MR and Mincha H: Enhancement of the antitumor efficacy of the anti-progestin, onapristone, by combination with the antiestrogen, ICI 164384. J Cancer Res Clin Oncol 120: 298-302, 1994.

23. Lydon JP, Ge G, Kitrell FS, Medina D and O'Malley BW: Endocrine and antitumor effects of combined treatment with an anti-progestin and antiestrogen or luteinizing hormone-releasing hormone agonist in female rats bearing mammary tumors. Cancer Res 59: 4276-4284, 1999.

24. Chatterton RT, Lydon JP, Mehta RG, Mateo ET, Pletz A and Jordan VC: Role of the progesterone receptor (PR) in susceptibility of mouse mammary gland to 7,12-dimethylbenz[a]anthracene-induced hormone-independent preneoplastic lesions in vitro. Cancer Lett 188: 47-52, 2002.

25. Romieu G, Mandelonde T, Ulmann A, et al: The anti-progestin RU486 in advanced breast cancer: preliminary clinical trial. Bull Cancer 74: 455-459, 1987.

26. Klijn JGM, de Jong FH, Bakker GH, Lamberts SWJ, Rodenburg CJ and Alexieva-Figusch J: Anti-progestins: a new form endocrine therapy for breast cancer. Cancer Res 49: 2851-2856, 1989.

27. Perrault D, Eisenhauer EA, Pritchard KL, et al: Phase II study of the progesterone antagonist mifepristone in patients with untreated metastatic breast carcinoma: a National Cancer Institute of Canada Clinical Trials Group study. J Clin Oncol 14: 2709-2712, 1996

28. Kettel LM, Murphy AA, Mortola AJ, Liu JH, Ulmann A and Yen SSC: Endocrine responses to long-term administration of the anti-progesterone RU486 in patients with pelvic endometriosis. Fertil Steril 56: 402-407, 1991.

29. Liu JH, Garzo G, Morris S, Stuenkel C, Ulmann A and Yen SSC Disruption of follicular maturation and delay of ovulation after administration of the anti-progesterone RU486. J Clin Endocrinol Metab 65: 1135-1140, 1987

30. Michna H, Schneider MR, Nishino Y and Etreby MF: The antitumor mechanism of progesterone antagonists is a receptor mediated antiproliferative effect by induction of terminal cell death. J Steroid Biochem 34: 447-553, 1989.

31. Forby B and Wiley TS: Progesterone inhibits growth and induces apoptosis in breast cancer cells: inverse effects on Bcl-2 and p53. Ann Clin Lab Sci 28: 360-369, 1998.

32. Bardon S, Vignon F, Montcourrier P and Rochefort H: Steroid receptor-mediated cytotoxicity of an antiestrogen and an antiprogestin in breast cancer cells. Cancer Res 47: 1441-1448, 1987.

33. Poole AJ, Li Y, Kim Y, Lin S-CJ, Lee W-H and Lee EY-H: Prevention of Brca-1-mediated mammary tumorigenesis in mice by a progesterone antagonist. Science 314: 1467-1470, 2006. 